\title{
Description of Technical Electives that Prepare Engineers for Careers in the Medical and Health Care Professions
}

\author{
Danny D. Mann ${ }^{1}$, Jacquie Ripat ${ }^{2}$, Arthur Quanbury ${ }^{2}$, Jason Morrison ${ }^{1}$, and Jitendra Paliwal ${ }^{1}$ \\ ${ }^{1}$ Department of Biosystems Engineering, University of Manitoba, Winnipeg, MB \\ ${ }^{2}$ Department of Occupational Therapy, University of Manitoba, Winnipeg, MB \\ Corresponding Author E-mail Address: Danny_Mann@umanitoba.ca
}

\begin{abstract}
In response to student interest in the broad field of biomedical engineering, the Department of Biosystems Engineering has developed three technical electives that now form the core of a Biomedical Specialization that is available to students in the Biosystems Engineering program at the University of Manitoba. These courses have been designed to help prepare engineers to meet the challenges of interacting with the medical and health professions. Required courses covering cell biology and physiology provide engineers with a fundamental understanding of living organisms. One cannot interact with medical and health professionals without this basic level of knowledge, however, this basic knowledge is not sufficient. To effectively work with medical and health professionals, engineers must understand the structure of these professions and the roles traditionally played by engineers in these professions. The paper will provide an in-depth description of these three courses. Students completing these courses are well prepared to work in the medical and health professions.
\end{abstract}

Keywords: biomedical engineering, healthcare industry, professional skills

\section{BIOMEDICAL SPECIALIZATION}

Engineers play a key role in the development of the technology that is around us every day and are experts at using technology to solve problems. However, the standard engineering curriculum does not expose engineering students to the unique challenges associated with the practice of engineering within the healthcare industry. The US Department of Labor has projected $72 \%$ growth in employment of biomedical engineers over the period from 2008 to 2018 (www.bls.gov/oco/ocos027.htm). In their words, "the aging of the population and a growing focus on health issues will drive demand for better medical devices and equipment designed by biomedical engineers." The biomedical industry in Manitoba is now looking to the biomedical industry in nearby Minneapolis to learn how to grow the industry in Manitoba. It is projected that engineering graduates will be needed to contribute to, and provide leadership within, the healthcare field and related industries.

In response to this projected need, the Department of Biosystems Engineering at the University of Manitoba introduced a Biomedical Specialization that is intended for those engineers interested in pursuing either graduate studies in biomedical engineering or an engineering career in the healthcare industry. The Biomedical Specialization consists of 27 credit hours of courses including 6 credit hours of required sciences (i.e., human anatomy and human physiology) and 12 credit hours of required technical electives offered by the Department of Biosystems Engineering. The remaining 9 credit hours are taken from a list of courses offered by other units on campus that have some relevance to the healthcare industry or biomedical engineering. The focus of this paper is to describe the three technical electives that have been developed by professors within the Department of Biosystems Engineering.

\section{DESIGN OF ASSISTIVE TECHNOLOGY DEVICES}

Three of the co-authors (D. Mann, J. Ripat and A. Quanbury) have developed an innovative undergraduate engineering class entitled "Design of Assistive Technology Devices" [2] which is modeled on the interdisciplinary approach used by practicing occupational therapists and rehabilitation engineers to identify suitable technological aids for an individual with a disability. Drawing on experiential learning theory and an interprofessional learning approach, engineering students in this unique course have benefitted greatly 
from the opportunity to participate in an interprofessional clinical assessment of a client with a disability. Participation in a clinical assessment gives the assessor an understanding of the unique abilities of the client, the environment in which the client lives and works, and the interaction between the client and the environment. All engineers working in the broad field of biomedical engineering (including rehabilitation engineering, medical device engineering, clinical engineering, medical imaging, and tissue engineering) will benefit from experiences of this nature as well.

The lecture content of the course focuses on three areas: the clinical assessment process, fundamentals of assistive technology devices, and the outcome assessment process. These three areas are covered under an overarching model called the HAAT model [1]. The HAAT model requires consideration of the human (client with a disability), the activity to be completed, and the assistive technology device to be used to achieve the desired activity. All three elements must be considered within the client's specific context. This model ensures that the technological device is not considered in isolation. Even though rehabilitation engineers may not be ultimately responsible for conducting a clinical assessment or outcome assessment, it is critical for the engineer to understand that an assistive technology device must be chosen to meet the specific needs of the client.

A four-part design project has been developed to ensure that students have an opportunity to experience the three areas covered in the course. First, students are required to complete a clinical assessment of an actual client. In most years, we have identified clients from the local community which provides an opportunity for students to interact with a real client. In the most recent offering of the course, the late Christy Brown was identified as the client. Students were able to conduct their clinical assessment using the movie entitled "My Left Foot." For the second part of the design project, students were required to design an appropriate assistive technology device for the client based on information generated from the clinical assessment. In this situation, "design" refers to one of the following: 1) selecting an existing device without modification, 2) modifying an existing device, or 3) creating a new device. The design report is required to include a description of the design, how it will be used by the client (based on the client's specific abilities), and any environmental modifications that may be necessary. For the third part of the design assignment, students must propose an assessment process that would be used to determine the appropriateness of the proposed design for the client. The final stage of the design project is a team effort to evaluate various proposed design options. Teams are required to complete the evaluation using the unranked paired-comparison technique and to submit a written report with the team's recommendations.
This course truly provides a unique learning experience for engineering students. An engineer is accustomed to designing devices for a client, however, the device is typically designed for the general public, or some subset of the general public. Designing an assistive technology device requires a change in thinking because the device must be appropriate for a unique individual having a set of unique abilities. One cannot generate the necessary information from a textbook or design handbook; the information can only be obtained through the clinical assessment process. It is critical that engineers understand this process and its limitations if they plan to work in this field.

\section{IMAGING AND SPECTROSCOPY FOR BIOSYSTEMS}

To cater to the needs of an increasingly large number of Biosystems Engineering undergraduate students wanting to take courses in the biomedical engineering area, J. Paliwal developed a $4^{\text {th }}$ year design elective called "Imaging and Spectroscopy for Biosystems". The purpose of the course is to familiarize senior Biosystems Engineering students with the fundamentals of imaging and spectroscopy as they relate to the various aspects of biomedical and biological engineering. In order for our students to understand the various diagnostic techniques of modern medicine, it is imperative that they understand the fundamental principles on which these techniques are based.

The course content is divided mainly into three areas, viz. theory of light, imaging, and spectroscopy. The first few lectures are devoted to the fundamentals of light and optics where we talk about the wave-particle duality, reflection, refraction, interference, polarization, human visual system, interaction of light with matter, and the formation and characterization of colours. The imaging part of the course deals with digital images, the process of image acquisition, imaging hardware (cameras and sensors, display screens, etc.), pre- and post-processing of digital images, noise removal and filtering. The relevance of these fundamentals is then linked to the applications in modalities such as X-rays, computed tomography (CT) scanning, optical coherence tomography (OCT), and positron emission tomography (PET). The focus of the spectroscopic techniques is mainly on vibrational (infrared and Raman) spectroscopy for diagnostic purposes. The last few lectures of the course are devoted to multivariate data analysis where we talk about chemometrics and artificial neural networks.

Another unique aspect of the course is that the students research a topic of their own choice and then deliver a mini-lecture followed by a mini-test to the rest of their classmates. This allows them to pursue a topic of interest in more depth. For most of their lab exercises they work 
in groups. Three of the labs are held off campus - two at the National Research Council and another one at the Health Sciences Centre.

The course offers the students with an opportunity to learn topics that have traditionally not been covered in the Biosystems Engineering curriculum. It is offered every other year and has already been taught three times now. The content and delivery methods have been tweaked based on the feedback from students. A number of students who have taken this course have gone on to pursue graduate degrees in biomedical engineering and have found tremendous value in this course. A course like this gives our students a very strong background in the area of imaging and spectroscopy techniques that form an essential component of biomedical engineering.

\section{BIOENGINEERING APPLICATIONS IN MEDICINE}

A third technical elective required by students in the Biomedical Specialization, called "Bioengineering Applications in Medicine", was developed by J. Morrison. This course was conceived, developed and delivered to ensure an understanding of technology, concepts and skills required in clinical engineering. Specifically the course builds student capacity to work as a professional engineer who has been trained in biosystems engineering and would be working in and contributing to the multidisciplinary field of clinical medicine. The course has two distinct components: the lectures that focus on essential knowledge relating to the role of engineers, technology and science in the development and application of medical treatments, hospitals and healthcare; and the design labs where team oriented design is applied to a "client's" problem and teams compete to develop and present their preliminary design as part of a conclusive bid on a fictitious contract to design, build and test prototypes for the client.

The focus of the lectures is to develop student understanding of biomedical engineering. A historical context of medicine and medical devices is introduced to ensure an understanding of the development of different professions (e.g., doctors, nurses, engineers and technicians) and the roles that engineers play within clinical and device development settings. Focus is subsequently shifted to laws and ethics involved with medical treatment, the modern definition of death, human experimentation, patient privacy and medical device development. From this base understanding the lectures move into more technical material, focusing on patient electrical safety, instrumentation, sensors, electrodes and biosensors.

Subsequently lectures adapt to have a more distinct biosystems (bioengineering) flavor with material on tissue reactions and wound response focusing on general biomaterials and orthopaedic biomaterials. Finally lecturing focuses on imaging methodologies, engineering developments and challenges in the design and operation of these devices and some fundamental physics of their operation. Midterm and final examinations are the core evaluation of the learning outcomes regarding the lecture material.

For the design labs, student teams begin with a vague client problem statement and work through three assignments that form a single design project. In winter of 2011 the client's problem statement was "Design a tantalum bead injector (inserter) for use with UmRSA or Halifax Biomedical systems that is easily loaded and used". This statement was given with a presentation showing two current solutions to the problem. The assignments then cover the first three phases of design as described by Dym and Little [3]: 1) problem definition; 2) requirements gathering with concept development; and 3) preliminary design. The first two assignments have deliverables that would be internal to their firm. The third is their bid submission for the project and documents their preliminary design. Note that they are bidding to be the engineering firm that works with the client to develop a complete design for the client, prototype it and perform mechanical and user testing with the prototypes.

The first deliverable is for each team to define their own group (i.e., students form their own teams) and their main objective (i.e., what they will accomplish/design). Subsequently the first assignment has the students tackle the problem by speculating and discovering the clients, users, stakeholders, potential users, environments of use and tasks performed on or with the device. A set of deliverables is required that details outcomes of their problem definition process relating to users, environments, tasks, objectives, metrics and constraints.

The objectives of the second assignment are to have the students study what is required of their design, how these requirements might be achieved, generate design alternatives, and assess these designs using the results of the problem definition process and choose a design to develop.

The third assignment is to establish their bid to develop the prototype from their preliminary design. This requires a technical bid be developed with concept drawings, an executive summary, budget, timeline, and the technical description, which includes the materials/parts list, assembly instructions, and cost estimate (per prototype).

The goal of these assignments is to focus on the early stages of design and the development of an idea in a fashion that supports decisions, documents process and ensures that alternatives are considered. By dividing the deliverables into those required for their internal purposes and those for the client the distinction is made that documentation has a variety of purposes and formats. In having the students bid for a contract a variety of issues 
are discussed and developed involving the workings of contracts, business operations, specifications and project development. Combined the lecture material and design time provides the students with a unique experience that is tailored to the application of engineering within the medical industry.

\section{CONCLUSIONS}

The general term of "biomedical engineering" covers numerous sub-areas. The Biomedical Specialization developed by the Department of Biosystems Engineering will not provide in-depth training in all of these sub-areas. Rather, we have strategically identified three areas that matched interests and/or expertise of faculty members (or collaborators from other departments). The pedagogical approaches used in these three courses are diverse yielding three diverse learning experiences for undergraduate students. The common element between the three courses, however, is that each contributes to the training of engineers for careers in the medical and health professions.

\section{References}

[1] Albert M. Cook and Jan Miller Polgar, Cook \& Hussey's Assistive Technologies Principles and Practice. St. Louis, MI: Mosby Elsevier, 2008 ( $3^{\text {rd }}$ ed.), 571 pp. \{ISBN: 978-0323-03907-9\}

[2] Danny D. Mann, Jacquie Ripat and Arthur Quanbury, "Interprofessional teaching teams: addressing emerging areas in Biosystems Engineering using a client-based learning project," Int. J. Engng Ed., vol 23, no. 4, pp. 691697, 2007.

[3] Clive L. Dym and Patrick Little, Engineering Design: A Project Based Introduction. Wiley 2008 ( $\left.3^{\text {rd }} \mathrm{ed}\right), 352 \mathrm{pp}$. \{ISBN:978-0-470-22596-7\}. 